H I G H L I GHTS

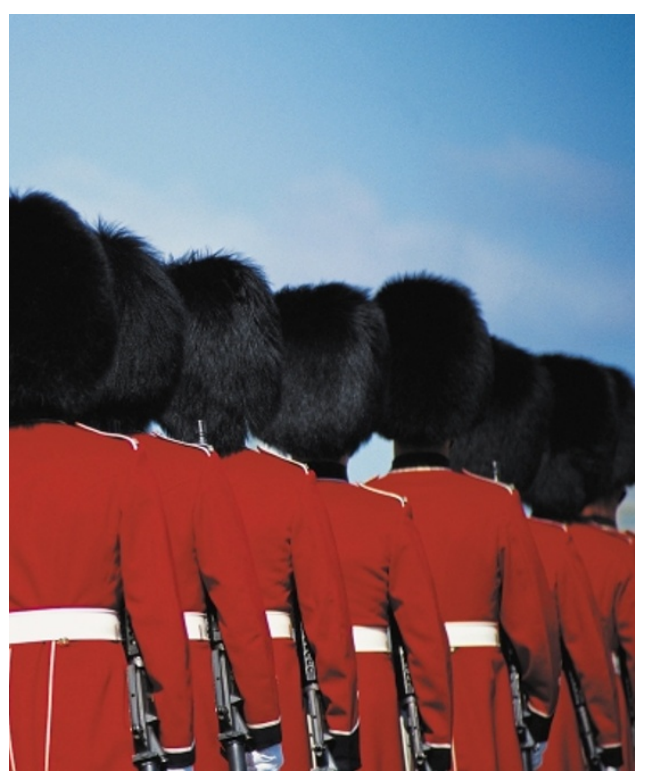

authors compared the fMRI activation produced by these movements with the sum of the activations produced when subjects moved either the wrist alone or the ankle alone.

The task that required the coordination of wrist and ankle movements caused increased activation in a network of brain areas, including the supplementary motor area, cingulate motor cortex, premotor cortex and cerebellum, indicating that this distributed network of motor areas is important for interlimb coordination. The authors then compared the two coordinated tasks - moving the wrist and ankle in the same direction or in opposite directions. Moving the two limbs in opposite directions is more difficult, and this was reflected in increased activation during this task. But, interestingly, the higher activation did not occur throughout the network - instead, it was limited to the supplementary motor area. This area has been implicated in bimanual coordination, but these new data provide evidence that it is also important for other types of limb coordination.

\section{Rachel Jones}

\section{(2) References and links} ORIGINAL RESEARCH PAPER Dietz, v. et al. Neuronal coordination of arm and leg movements during human locomotion. Eur. J. Neurosci. 14 1906-1914 (2001) | Debaere, P. et al. Brain areas involved in interlimb coordination: a distributed network. Neuroimage 14, 947-958 (2001)

\section{WEB SITES}

Encyclopedia of Life Sciences :

http://www.els.net/

locomotion | motor system organization

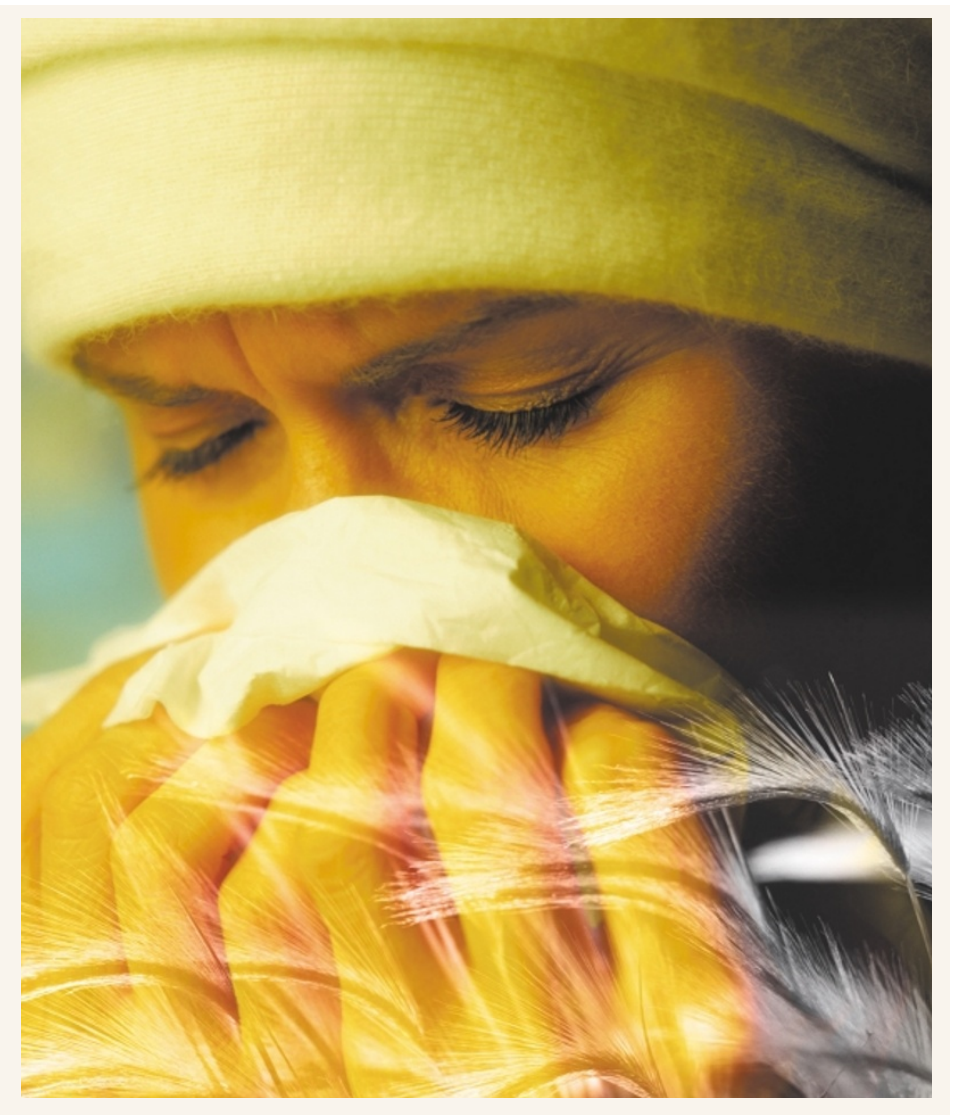

\section{IN BRIEF}

\section{NEURODEGENERATIVE DISEASES}

Recruitment and activation of caspase- 8 by the Huntingtin-interacting protein Hip-1 and a novel partner Hippi.

Gervais, F. G. et al. Nature Cell Biol. 14 January 2002 (10.1038/ncb735)

It is not clear why expansion of the polyglutamine repeats in the protein huntingtin causes striatal neurons to die in Huntington's disease. Gervais et al. have cloned a new protein that might be important in this process. Normal huntingtin binds to another protein, Hip1, but expanded huntingtin binds less tightly, releasing Hip1 to interact with the newly identified protein, Hippi. The complex of Hip1 and Hippi can recruit procaspase 8 to activate an apoptotic pathway, which could lead to cell death.

\section{SYNAPTIC PLASTICITY}

Long-term potentiation and contextual fear conditioning increase neuronal glutamate uptake.

Levenson, J. et al. Nature Neurosci. 14 January 2002 (10.1038/nn791)

Glutamate transporters serve important functions at synaptic clefts, controlling the time course and concentration of glutamate after its release. Levenson et al. report that the induction of long-term potentiation (LTP) in area CA1 of the rat hippocampus causes an NMDA-receptor-dependent increase in glutamate uptake, and that LTP is also associated with translocation of the glutamate transporter from the cytosol to the membrane. An increase in glutamate uptake also occurred in rats during contextual fear conditioning, a hippocampus-dependent form of learning.

\section{DEVELOPMENT}

Opponent activities of Shh and BMP signaling during floor plate induction in vivo.

Patten, I. \& Placzek, M. Curr. Biol. 12, 47-52 (2002)

Induction of the floor plate during vertebrate development depends on the secreted molecule sonic hedgehog (Shh), but Patten and Placzek now show that exogenous Shh alone cannot induce an ectopic floor plate in the embryonic chick neural tube in vivo. However, when Shh was applied with chordin, an antagonist of bone morphogenetic protein (BMP) that is normally expressed in the notochord, a floor plate was induced. It is proposed that dorsally derived BMPs can affect even the most ventral parts of the neural plate, unless they are antagonized by notochord-derived signals.

\section{CIRCADIAN RHYTHMS}

Posttranslational mechanisms regulate the mammalian circadian clock.

\section{Lee, C. et al. Cell 107, 855-867 (2001)}

The authors find that the mouse circadian clock seems to be regulated by robust post-translational mechanisms. Per1, Per2, Clock and Bmal1 undergo circadian changes in phosphorylation, and these, together with patterns of protein abundance, subcellular localization and protein interactions, seem to be crucial for maintenance of the circadian clock. 